\title{
THE DEVELOPMENT OF CONTENT KNOWLEDGE THROUGH TEACHING PRACTICE
}

Dorothy Worden

University of Idaho

Moscow, ID, USA

\begin{abstract}
Research on the unique nature of teachers' subject matter knowledge and how this knowledge interacts with other domains of the knowledge base for teaching has been an extremely productive field of inquiry since the mid 1980's. In particular, Shulman's (1987) construct of pedagogical content knowledge (PCK) has been taken up by researchers to describe the subject specific knowledge of teachers in a variety of disciplines. Yet while this concept has been widely applied to describe expert teachers' knowledge, much less research has examined how PCK develops in and through teaching practice. To address this need, the present study examines how one teacher's understanding of a pedagogical genre developed through her first semester of teaching a post-secondary second language (L2) writing class. Drawing on a sociocultural theoretical (SCT) perspective, this study traces the development of a single subject matter concept, points of analysis, as it emerges in teaching activity, is mediated by the teacher's interactions with her students and the researcher, and is eventually incorporated into her knowledge of the analytic essay genre and how to teach it.
\end{abstract}

Keywords: Pedagogical content knowledge; sociocultural theory; concept development; L2 writing

\section{Teachers' Knowledge of Content for Teaching}

What teachers know about the content they teach has been an important area of study in teacher cognition research since the 1980's. Of particular relevance for the present study is Shulman's (1987) concept of pedagogical content knowledge (PCK). PCK represents the unique nature of teachers' knowledge of content. While teachers possess expert content knowledge of the major facts, theories, and methods of a particular academic field, much as non-teaching content experts would, they additionally possess the knowledge of how to represent particular content in pedagogically appropriate ways to particular students in particular educational contexts. This dynamic integration of knowledge of content, students, pedagogy, and educational contexts is PCK, which constitutes the unique professional knowledge of teachers.

Since its introduction, several modifications and clarifications to the concept of PCK have been proposed. One of the major trends in this research has been a focus on the role of the teacher herself in the transformation of content knowledge and general pedagogical knowledge into PCK. Such studies have focused on how teachers' content-related values (Gudmundsdottir, 1990) and beliefs about the purposes and value of studying a particular subject (Grossman, 1990) influence their PCK. These studies demonstrate that the activity of transforming content for teaching is not some clinically rational process. Rather, teachers experience it as fraught with competing values, visions, goals, and emotions that must be delicately balanced.

In addition to the expanded focus on the moral and affective components of teachers' PCK development, other research has clarified the nature of the content knowledge teachers transform into PCK. The work of Ball and her colleagues represent a unique line of research in this vein. Focusing on math education, particularly at the elementary school level, their work

\footnotetext{
* Dorothy Worden is an Instructor of Applied Linguistics at the University of Idaho. Her research and teaching interests include second language teacher cognition, teacher education, and multilingual writing. She has previously published in Teaching/Writing: The Journal of Writing Teacher Education (2015), Language and Sociocultural Theory (2014), and Assessing Writing (2009). Email: dorothy.worden@gmail.com
} 
has empirically investigated the nature of the content knowledge needed for teaching (Ball, Thames, \& Phelps, 2008). In particular, the researchers have identified two different categories of content knowledge that the teachers draw on in their work. The first, common content knowledge, refers to the knowledge that teachers need and use on a regular basis but that is also used in settings outside of teaching. The second category, specialized content knowledge, is a particular kind of content knowledge that teachers possess that is not typically used in other settings. However, unlike PCK, specialized content knowledge does not directly relate to either a teacher's knowledge of students or of instructional practices. Instead, the authors describe specialized content knowledge as an "unpacked" or "decompressed" form of knowledge (p. 400). An important aspect of developing knowledge for teaching, then, is not only transforming content knowledge into PCK, but also unpacking one's content knowledge to make it available for such transformation.

While the framework of teacher knowledge proposed by Shulman (1987) and subsequently developed by other researchers has been an influential concept in teacher cognition research, it has not been without its critiques. First, critics have argued that research in this framework has largely focused on individual teachers and has not adequately accounted for the role of communities and teaching contexts in teachers' knowledge (Sockett, 1987; Shulman \& Shulman, 2004; Ellis, 2007). The second major critique of the PCK framework and subsequent research has been that it reifies knowledge, treating it as static and stable, and as a result has not paid sufficient attention to the teachers' thinking and learning processes (Sockett, 1987, Cochran, DeRuiter, \& King, 1993; Fenstermacher, 1994; Hashweh, 2005; Ellis, 2007). This lack of attention to teachers' knowledge development has limited our ability to use PCK as a tool to explicitly scaffold and assess teacher development (Park \& Oliver, 2008) and has led to a research agenda that tends to focus "on knowledge at the expense of thinking processes" (Hashweh, 2005, p. 280).

Overall, these two overlapping critiques of the PCK framework point to a need to reconceptualize teachers' subject matter knowledge as dynamic and emergent in the varying professional contexts in which teachers learn and work. There is a need for research that examines teachers' PCK in development, rather than in its more stabilized form, and this research should focus on development through engagement in professional contexts and activities, including teaching practice itself. Unfortunately, little research that examines PCK from this developmental and situated perspective exists. The little research that does examine the development of PCK in teaching practice has been unanimous in highlighting the difficult and uneven nature of such knowledge development. Such studies have emphasized the importance of a strong conceptual framework into which teachers' new insights gained through teaching can be incorporated (Grossman, 1990) but note that this conceptual framework is often lacking due to the limited and inappropriate content preparation many teachers experience (Grossman, Wilson, \& Shulman, 1989; Ball, 2000). In particular, the division between content and pedagogy courses present in so many teacher education programs effectively means that teachers are expected to integrate their knowledge of pedagogy and content independently when they enter the classroom. Unfortunately, research has demonstrated that this integration does not always happen (see Ball, 2000; Grossman, 1990). In short, researchers have found that "Learning from experience is neither as automatic nor as effortless as new teachers might like to believe" (Grossman, 1990, p. 109) and that when it does occur it "can be haphazard, dependent to a certain extent on chance" (Grossman, 1990, p. 49).

The influential concept of PCK and its subsequent developments have pushed educational researchers and teacher educators to take teachers' knowledge, and particularly their subject matter knowledge, seriously. Yet need remains for studies that do more to examine how PCK develops through teaching activity. Such studies need to account for the dynamic, contextual, emergent, and communal nature of teachers' PCK both as it initially develops in preservice teacher education and crucially as it continues to develop through teachers' ongoing engagement with the processes of pedagogical reasoning. Such studies may be able to 
shed light on the difficult and seemingly haphazard process by which teachers learn from their classroom experiences. Understanding what factors contribute to and perhaps hinder such teacher learning can, in turn, inform teacher educators' efforts to prepare teachers for, and support them in, ongoing PCK development.

\section{Sociocultural Theory and Concept Development}

Vygotsky's work, and subsequent sociocultural theory (SCT) and research that expands on it, provides a robust theoretical framework that allows researchers to take the developmental and situated perspective on teachers' knowledge that has been lacking in much of the previous research in the PCK framework. SCT is characterized by three interrelated principles: the origins of human cognition in social interaction; the importance of studying human cognition in the process of development rather than in its finished state (also referred to as the genetic method); and the principle that human cognition is mediated by cultural and symbolic tools such as language (Vygotsky, 1986; Wertsch, 1985, 1989; Lantolf \& Thorne, 2006).

These three related concepts provide a useful analytical lens for examining the process by which teachers learn in activity (Johnson, 2009; Smagorinsky, Cook, \& Johnson, 2002). First, by emphasizing the study of cognition as it develops in interaction, an SCT approach promotes a view of teacher knowledge as dynamic and situated. This conceptualization avoids many of the epistemological problems that have been associated with teacher knowledge research (Hashweh, 2005; Ellis, 2007; Park \& Oliver, 2008). Second, the genetic method provides a methodology for examining development across multiple timescales. SCT research examines the development of the human species, the development of human culture, development across a single person's lifetime, and development of a single concept, or microgenesis (Vygotsky, 1986; Wertsch, 1985; Lantolf \& Thorne, 2006). This emphasis on development across timescales provides a means of examining both how teachers' knowledge develops in the course of individual interactions as well as across longer time periods. Third, the concept of mediation in SCT provides a rich theoretical framework for understanding the relationship between a teachers' developing knowledge and the social contexts and interactions in and through which such knowledge develops. For Vygotsky (1986), mediation is the process whereby a person encounters and makes use of a variety of tools in the external and social plane in order to regulate his or her own thinking and activity. Such mediation comes in the form of symbolic tools, most notably language, as well as social interactions with expert others. To the extent that individuals are able to internalize these tools, they can then consciously and reflectively use them to direct and regulate their own thinking and behavior.

Of particular value in illuminating how teachers' CK and PCK may develop in teaching activity is Vygotsky's work on concept development. Vygotsky's (1986) distinction between spontaneous and scientific concepts provides insight into the changing nature of teachers' concepts as they develop. Spontaneous concepts are those concepts that develop through our day to day experiences in the world. The structure of such concepts is therefore concrete and empirical in nature. Scientific concepts in contrast are systematic, hierarchical, and logical and are typically learned in formal instructional contexts. Vygotsky (1986) does not privilege one type of concept over the other, but sees either as insufficient for full self-regulation. Spontaneous concepts are rarely consciously held and therefore are not readily available for reflection and critique. Scientific concepts, on the other hand, are consciously held but can become stuck in their initial verbal definition form if never connected to concrete experience. For Vygotsky (1986), the ultimate goal of concept development then is for spontaneous and scientific concepts to become united into true concepts. This occurs as the scientific concept is repeatedly applied to concrete situations and the spontaneous concept becomes abstracted through processes of generalization. This process of concept development has been shown to be an uneven one in which teachers' knowledge of a given concept continues to develop even after the external signs associated with a particular 
concept have already been mastered (Smagorinsky, Cook, \& Johnson, 2002). From this view, teachers' development of subject matter concepts for teaching purposes involves not only learning to use relevant terms and strategies in teaching activity but also the ongoing process of "coming to understand the meaning and functional significance of the sign forms one has been using all along" (Wertsch, 2007, p. 186).

Drawing on these key concepts from Vygotskian sociocultural theory and following recent calls for research that examines teachers' knowledge as it emerges in social activity (Cochran, DeRuiter, \& King, 1993; Hashweh, 2005; Ellis, 2007; Park \& Oliver, 2008), the present study examines the development of a single concept, points of analysis, as it emerges in one teacher's teaching activity, is mediated by the teacher's interactions with her students and the researcher, and is eventually incorporated into her overall content knowledge and pedagogical content knowledge of the writing class.

\section{The Study}

\subsection{Context}

The case study presented here is drawn from a larger study examining the development of content knowledge for teaching among four first-time teachers of an L2 first year writing course at a large public university in the northeastern United States. The general goal of the first year writing course is to prepare undergraduate students for the academic reading and writing tasks they will encounter in their college careers. The major assignments of the course consisted of four pedagogical genres: the extended definition essay, the comparison/ contrast poster presentation, the analytic essay, and the researched argument essay.

Data collection lasted for one 16-week semester with the majority of the data collection taking place during the unit focusing on the third of four required essays - the analytic essay. According to the instructor handbook, the analytic essay genre is a researchbased report that would "answer the questions of Who? When? What? Where? and Why?" while also demonstrating students' ability to "go beyond these questions to suggest which points are most relevant for understanding what really happened, according to the source material" (Verity, 2013, pp. 9-10).

\subsection{Focus Teacher}

The analysis presented here focuses on the experiences of one teacher, Sonja, as she taught the analytic essay for the first time. Sonja was a first semester student in a Ph.D. program in Applied Linguistics at the time of the study. She was an experienced language teacher, having taught ESL and Russian as a foreign/ heritage language for nine years prior to data collection. Sonja had taught writing before in the context of her Russian language classes, but this was her first time teaching an ESL first year writing course.

\subsection{Data Sources and Collection}

In order to get a rich a picture of Sonja's knowledge development over the course of the semester, this study used a qualitative approach. The analysis presented here relies on four sources of data.

\section{Semi-structured interviews}

Five semi-structured interviews were conducted over the course of the semester. The interviews focused on Sonja's background as a writer and teacher, her understanding of the content and curriculum of the course, and her knowledge of the focus instructional unit of the analytic essay. The interviews typically lasted approximately one hour and were all audio recorded.

\section{Concept maps}

As part of the semi-structured interviews, Sonja was asked to complete six concept maps (one each for interviews 1-4 and two for interview 5). There were three basic concept map prompts which Sonja was asked to respond to twice, both before and after the focus instructional unit (concept maps 3 and 4 ) and at the beginning and end of the semester (concept maps 1, 2, 5, and 6). For each concept map, Sonja explained her concept map as she drew it and these explanations were video recorded. 
3. Video recordings of instruction

During the teaching of the third of four required papers, the analytic essay, I attended and video-recorded all of the seven class sessions.

\section{Stimulated recalls}

During the course of the analytic essay unit, Sonja participated in three audio-recorded stimulated recalls. For these stimulated recalls, I chose excerpts from the video-recordings of her class that focused on some aspect of the content being taught. In choosing these excerpts, I focused particularly on Sonja's explanations of content, student contributions and questions about content, and moments of apparent confusion or difficulty on the part of Sonja or the students. The conversations in the stimulated recall sessions tended to be quite free-flowing, and the direction was determined largely by Sonja's emerging reflections. However, I also created a bank of reflection questions that I shared with Sonja and used as prompts to start the discussion of each excerpt (see appendix A).

The final stimulated recall occurred while Sonja was evaluating her students' final drafts of the analytical essay. For this stimulated recall, I asked Sonja to select three student drafts that represented high, middle, and low examples in terms of how well the texts met her goals for this particular assignment. Sonja was then asked to comment on what she saw as the strong and weak elements of each draft.

\subsection{Data Analysis}

Following data collection, all the interviews, concept maps, stimulated recalls, and classroom teaching excerpts focused on in the stimulated recalls were transcribed using broad verbatim transcription conventions (appendix B). I then conducted a microgenetic analysis of Sonja's developing understanding of the content of this instructional unit. I examined every instance in which Sonja externalized her understanding of the genre of the analytic essay as expressed in the interviews, her instructional talk in the classroom, reflections on her teaching in the stimulated recall, and visual representations of the content in the concept maps. In particular, this analysis examines the development of a single concept, points of analysis ${ }^{1}$, from the beginning of the unit to the end. I trace how the shifting terms Sonja applied to the concept and the various definitions and paraphrases she used over the course of her teaching and the stimulated recalls demonstrate changes in her understanding of this concept. I additionally examine how her interactions with both her students and with myself as a researcher mediated her developing conceptualization.

\section{Findings}

\subsection{Pre-teaching Knowledge of the Analytic Essay}

In order to understand the developmental trajectory of the concept of points of analysis in Sonja's thinking over the course of this unit, it is important to get a sense of how Sonja understood the overall content of the unit prior to teaching. From the beginning of the semester, Sonja identified the analytic essay unit as "my major (.) challenge" within the curriculum (interview 2, 9/6/2013). One reason for this challenge was Sonja's own lack of explicit knowledge of the genre. Sonja described herself as having a "a good intuitive understanding of what a good analytical essay is," but didn't "necessarily know how to explain that to students" (stimulated recall $1,10 / 11 / 2013)$. In other words, while Sonja possessed content knowledge, she had not yet transformed that content knowledge into pedagogically appropriate forms for her students. Furthermore, Sonja herself interpreted the challenge posed by the analytic essay as being not merely a matter of representation. Instead, Sonja viewed her difficulty articulating the concept as evidence that she herself did not yet fully understand it, explaining her general belief that "if I struggle with explaining something that means it's not completely (.) cl- like I don't have a very com- a very clear idea" (stimulated recall 1, 10/11/2013).

This difficulty of putting her intuitive understanding of the genre into explicit language is demonstrated by the relatively unelaborated definition of the genre she 
offered in the course of the interview just prior to the start of the analytic essay unit.

\section{Excerpt 1:}

1 Sonja: the way that I understand what analytic essay is is when you um uh when you take an issue (.) that is clearly controversial, or debatable, or (.) just kind of (.) doesn't sit well with people, and you explicate it. you learn all you can about it. a:nd (.) it is (.) an important, an extremely important academic skill and also just (.) sort of life skill, (.) not to jump to conclusions, to start argue right away. (interview 3, 10/02/2013)

Sonja's definition of the genre includes a description of the typical content (1-2) and the importance of analysis for her students' future studies and lives (4-5). Yet her explanation of what analysis actually involves is relatively unelaborated. She describes analysis as simply researching and explicating an issue (3-4) and contrasts it with the more familiar rhetorical mode of argumentation (5-6), but does not describe the process of analysis in detail.

In Vygotskian terms, Sonja's understanding of the analytic essay genre at this point is clearly a spontaneous concept. Because it derives from her everyday experiences as a writer and reader, her understanding of the genre is largely intuitive. As Sonja herself notes, while this intuitive knowledge of the genre may be perfectly serviceable for her as a writer, as a teacher she needs to be able to explain the concept to her students. This requires that she find a way to unpack her intuitive content knowledge into the explicit specialized content knowledge needed for teaching (Ball, Thames, \& Phelps, 2008), or, to put it another way, she needs to move from her spontaneous concept to a true concept through a process of generalization.

\subsection{A Concept Emerging in Teaching Activity}

It was with this "intuitive" knowledge of the genre that Sonja began teaching the unit. As she taught, one concept in particular, what she came to eventually refer to as points of analysis, developed as a way of explaining the process of analysis. This concept emerged in the midst of Sonja's teaching on the first day of the unit. This class period focused on analyzing a model essay from the course textbook (Gupta, 2012). Sonja spent the first half of the class leading the students through a discussion of this text focusing on collaboratively summarizing the content and analyzing the rhetorical purpose. In the midst of this discussion, Sonja marked a deliberate deviation from her planned lesson in order to address the emerging concept of points of analysis. In this excerpt, S2 is responding to Sonja's question regarding why this article can be considered an analytic essay.

\section{Excerpt 2:}

1 S2: he gives examples of different article:s and studies that have been done in other universities, about why this happens, and how as people go through different stages of life, they stop exercising, like for example, like [S1] said, when you start college you have- it's a whole new experience and you have less time so you stop exercising and you start giving excuses?

6 Sonja: $\mathrm{mhm} \mathrm{mhm}$. okay. so I'm sort of (.) deviating from my plan because (.) our

7 discussion's actually- (.) but it's going in the right direction, just slightly (.)

8 shaping up slight- slightly differently. but I like that. cause you seem to (.) to

9 really: (.) understand the idea of analyticof an analytic essay. so what I want us

10 to do guys right now is (.) open your books, grab a partner (.) so one two, one

11 two, one two, one two, one two, one two, ((continues counting silently)) perfect.

12 that means we are missing someone. (.) okay so (.) grab your partner and look in 

pencil a:ll the: (2) evidence- this is what (S2) just said, he listed like all of this (3) evidence from (.) elsewhere, right? find those instances of support (.) tha:t Gupta brings into (.) his analysis. or like what are these-

17 Sonja: container gesture with both hands, two beats

18 Sonja: thin- what are the components that he analyzes?

19 (2)

20 Sonja: okay?

$21 \quad(2)$

22 Sonja: does that make sense? what are the things, elements (.) o:f (.) no(h)t wanting to exercise or not exercising does he ananalyze? (class session, 10/7/2013)

In this excerpt, it is clear that the concept of points of analysis emerged in the context of the teaching itself. In response to S2's explanation of why the article could be considered an analytic essay (1-5), Sonja announces her intention to deviate from the lesson plan (6) before introducing the concept of points of analysis within the context of a spontaneous pair assignment for the students (9-16). While she could not articulate a single motivating reason for her in-flight decision, saying that "I wish I could provide a logical explanation," Sonja did confirm that the concept of points of analysis was one that had occurred to her in the class itself. She explains that "this idea came to me as I was talking about this article. right? I really did not think about this (.) before (.) uh or as I was preparing for the class or as I was reading the article" (stimulated recall 1, 10/11/2013).

Moreover, even as Sonja begins to use this concept in teaching, it is clear that her own understanding of the concept is still in development. Throughout the excerpt, we can see Sonja struggle to articulate this concept verbally to her students. In her first attempt to communicate the concept, Sonja does not use words at all but instead produces a container gesture in the absence of speech as she searches for an appropriate term (17). Even when she does attach language to the concept, the terms she uses shift rapidly. She refers to the concept first as "things" (18) then "components" (18) then back to "things" (22) then "elements" (22). The shifting terminology demonstrated in Sonja's talk does not merely indicate that Sonja is searching for a pedagogically appropriate representation of an established concept. In other words, Sonja is not merely transforming her existing content knowledge into PCK. Rather, through this search, she is attempting to externalize this concept for the first time. Sonja herself confirms this as we discussed this excerpt in the first stimulated recall.

\section{Excerpt 3:}

1 Sonja: I don't even like this (.) uh term element of analysis. I don't know what to call

2 it. and this is an issue because (.) I really don't- I haven't read enough about (.)

3 what an analytical essay is, how it is $4 \quad$ metalanguage to (.) talk about it or think about it. so that- I'm coming up with 5 this (.) as I go through this exercise with my students. (Sonja, stimulated recall 1 , 6 $10 / 11 / 2013)$

Sonja acknowledges her difficulty putting the concept into language, noting that she is still not entirely satisfied with the term she used but is struggling to find the appropriate metalanguage to explain the concept to her students. She attributes this problem to her own lack of knowledge about the analytic essay, resulting in a situation in which Sonja is "coming up with" the concept in the act of teaching itself (4-5). What Sonja is describing here is her lack of a scientific concept of points of analysis. In one sense, Sonja knows what a point of analysis is, but this knowledge is a spontaneous concept based in her writing experiences. However, what Sonja needs in order to teach is not this tacit, largely unexamined spontaneous concept but rather an unpacked, explicit, and systematic scientific concept that she believes she could gain through reading more formal explanations of the genre. It is particularly important to note here that Sonja describes this lack of 
metalanguage as inhibiting not only her ability to "talk about" the concept, but her ability to "think about it" as well (4-5). From an SCT perspective, which emphasizes the dialectical relationship between thought and word, this difficulty makes sense. Words, for Vygotsky (1986), are not merely external expressions of fully formed thoughts. Instead, the process of putting a thought into words necessarily changes the thought in fundamental ways as the thought "does not merely find expression in speech; it finds its reality and form" (p. 219). From this viewpoint, Sonja's struggle to find the language to express this concept is not merely an issue of choosing vocabulary to attach to a pre-existing concept in her mind. Rather, the very process of externalizing her thinking, of taking her spontaneous concept of these points of analysis and making them explicit and systematic for her students, is transforming how she herself conceptualizes them.

\subsection{Mediation and Concept Development}

As Sonja continued to use the developing concept of points of analysis in her teaching, her conceptualization was mediated by several tools. These included the required curriculum, the readings and models she assigned and conversations with fellow teachers among others. For the purposes of this analysis, I will focus on two sources of mediation that impacted how Sonja conceptualized points of analysis and explained it to her students - her interactions with her students and the guided reflection of the stimulated recalls.

\subsubsection{Mediation through Interactions with Students}

As Sonja used the concept of points of analysis in the classroom, her students' own emerging understanding (and misunderstandings) of the concept played a mediating role in how she understood and taught the concept. Following the initial introduction of the concept in the first class (excerpt 2), Sonja gave her students some time to examine the model essay looking for these points of analysis. As she brought the

group back together to discuss their findings, Sonja rearticulated her question, eliciting students' ideas regarding what these points of analysis are in the context of the model essay. The students' responses further shape Sonja's developing concept and pedagogical representation of the concept by introducing the role of rhetorical purpose in the conceptualization of points of analysis.

\section{Excerpt 4:}

1 Sonja: so what was the first thing that (.) the first sort of component of his analysis?

$2 \quad[\ldots]$

3 S1: uh ((reading from text)) sixty percent of American adults do not exercise, and more than seventy-two million are obese?

5 Sonja: do you think that was an element?

6 S1: um I think it was just because it- like it gives you background on like- it just

11 S2: to make people realize that it is an issue?

12 Sonja: yeah, don't you think this was more of a: (.) $\operatorname{mag}[$ ne:t?]

13 S3: [magnet,] yeah.

14 Sonja: ((while writing "Magnet" on board)) this was part of introduction right?

15 Sonja: cause if we say that the <pur: pose of this essay is to analyze why $>$ (.) so the elements of analysis are not going to be (.) how many people do or do not analyze, right? we're trying to answer a question why? (.) and those components (.) are gonna be something else, right?

(Sonja, 10/7/2013)

Sonja responds to S1's misunderstanding of the concept through taking up his own focus on the rhetorical purpose of a section of text to further 
articulate the concept. In response to Sonja's request for a volunteer to offer the first "component of his analysis" in the essay (1-2), S1 responds by reading a specific statistic cited in the first paragraph of the text as a possible "component" (4-5) and, in response to Sonja's follow up question (6), explains his reasoning for this selection (7-9). S1's contributions here highlight his understanding of the emerging concept of points of analysis. Identifying the statistic as a "component" suggests that this student understands a point of analysis as being essentially the same thing as a piece of evidence. Moreover, his explanation of why he identified this excerpt as a point of analysis focuses on what the excerpt does in the text or its rhetorical purpose -in this case, providing background and establishing the relevance of the topic (7-9).

While it is clear from Sonja's response that she views this students' conceptualization as incorrect, she takes up his reasoning regarding the connection between a point of analysis and rhetorical purpose, asking S1 to more directly explain "the purpose of these statistics" (10) and then renaming the section as a "magnet" rather than a point of analysis (13). Sonja also incorporates this students' focus on the rhetorical purpose of a selection of text into a new explanation of the concept of a point of analysis. Sonja begins by rearticulating that "the <pur: pose of this essay is to analyze why>" and as a result, the components of analysis cannot be something that fulfill a different rhetorical purpose, such as attracting a reader's attention. Instead, "those components (.) are gonna be something else" (lines 24-27).

This renewed attempt to explain theconcept of apoint of analysis with regard to the overall purpose of the essay demonstrates how Sonja is aligning her instructional language with the emerging understandings of the students. This interaction certainly functions as mediation for the students' emerging understanding of the concept, but it also shapes the teacher's developing knowledge. As the students attempt to articulate and use the concept of points of analysis, Sonja uses their contributions to begin to create a shared metalanguage to talk about the concept. In this way, Sonja and her students collaboratively construct this concept through the process of talking about it.

\subsubsection{Mediation through Guided Reflection}

In addition to the development of the concept that occurred within the class itself, reflecting on her teaching in the stimulated recall sessions had a further impact on Sonja's developing concept of the points of analysis. The multiple opportunities to externalize her understanding of the concept and receive dialogic mediation from the researcher (R) helped Sonja to develop her understanding of and ability to talk about the concept of points of analysis, developing a new and influential sub-concept within the context of the stimulated recalls.

In excerpt 5 , Sonja is responding to my request to explain the concept of "an element of analysis" not as though she was "describing it to a student" but rather to another content expert (stimulated recall 1, 10/11/2013). By phrasing the question this way, I am inviting Sonja to share her content knowledge - her own understanding of the concept as an expert to another expert - without having to concern herself with transforming this knowledge into appropriate forms for students.

\section{Excerpt 5:}

1 Sonja: in the analytical essays (.) and specifically in articles that (.) uh (.) that I asked

11 R: identifying them?

12 Sonja: yeah yeah exactly and this is what they did in in this in the assignment for today 13 so they $\mathrm{j}$ - they gave me a topic and they told me I'm gonna look at (.) social 
14

15 R: oh so when they write as well

16 Sonja: s- (.) right right right. and so (.) I want them to uh to see an issue as a complex one consisting of a number of (.) elements. um (.) and those (.) elements need to be looked at (.) from different perspectives (.) sort of a thing. (stimulated recall $1,10 / 11 / 2013)$.

Here, Sonja again continues to struggle with metalanguage and asks for my input regarding possible terms (6). Rather than providing possible terms, I instead suggest another "way to think about it," by asking her to focus on what she wants her students to do with the concept (7-8). Sonja responds that she wants her students to use the concept of points of analysis as writers, rather than simply identifying them as readers (12-14). She references a recent homework assignment in which the students explained how they would analyze their topics in terms of "looking at" different "components" of the issue (13-14). It is in this mode of describing what she wants her students to do with the concept of points of analysis, that Sonja brings a new dimension to the developing pedagogical concept. She describes her goals for her students, saying that "I want them to uh to see an issue as a complex one consisting of a number of (.) elements. um (.) and those (.) elements need to be looked at (.) from different perspectives" (16-18). The term "perspectives" does not appear anywhere in Sonja' preceding talk, either in the classroom or earlier in the stimulated recall. This new term is here added to the existing term of "elements" to describe two different aspects of the process of analysis. The relationship between these two sub-concepts is that the "elements" refer to the parts of a complex issue whereas "perspectives" refers to what an author does with and to those elements.

Even within this stimulated recall session, Sonja uses this new concept of "perspectives" as a new way to talk about points of analysis. In the following excerpt, Sonja is reflecting on an activity from the second day of class in which she asked the students to identify the points of analysis in a second model essay (Luhrmann,
2013). While Sonja had used the term "units of analysis" in the actual class period, in her reflections in the stimulated recall Sonja described the text as being composed of various "perspectives" rather than "units."

\section{Excerpt 6:}

1 R: okay. s:o (.) any comments on that? what you were trying to do there? (.) same

2 thing basically or [something different?]

3 Sonja: [yeah yeah again] the same idea that uh okay we uh (.) there is

4 this phenomenon of hearing voices right? sound hallucinations. so how do we

$5 \quad$ look at it? from what kinds of like what kinds of perspectives can we bring

6 into an analysis of iss- of this issue? uh, we can look at it from this cultural

7 perspective, we can look at this (.) issue from: this perspective of how do you deal

8 with those? uh (.) medically or therapeutically (.) or pharmaceutically versus

9 therapeutically. engaging with voices (.) um and so that these were to me (.) uh perspectives that she brings into the analysis of hearing voices.

11 R: alright let's see:

12 Sonja: maybe I will find a good way to talk about it finally if we talk about it long enough ((laughter)) (stimulated recall 1 , $10 / 11 / 2013)$.

Here, rather than discussing the model text in terms of "units" she focuses on "what kinds of perspectives can we bring into an analysis of iss- of this issue?" (56). This new term of "perspectives," which emerged in the co-reflection of the stimulated recall, is now being retroactively applied to previous classroom interactions in which it was not actually used. Sonja's final comment that "maybe I will find a good way to talk about it finally if we talk about it long enough" (13-14) demonstrates her own awareness that the act of reflecting verbally on the concept and how to teach it is in turn shaping her language, and indeed her own understanding. 


\subsection{Post-Teaching CK and PCK of Analytic Essay}

The concept of points of analysis and particularly the new term of "perspectives" remains important in Sonja's thinking about her teaching throughout the remainder of the unit and beyond. Her comments in the postteaching interview demonstrate the extent to which this spontaneous concept which emerged in teaching activity has become a central element of her knowledge of the genre and how to teach it. The integration of this concept into her PCK is best demonstrated by her postteaching concept map (figure 1).

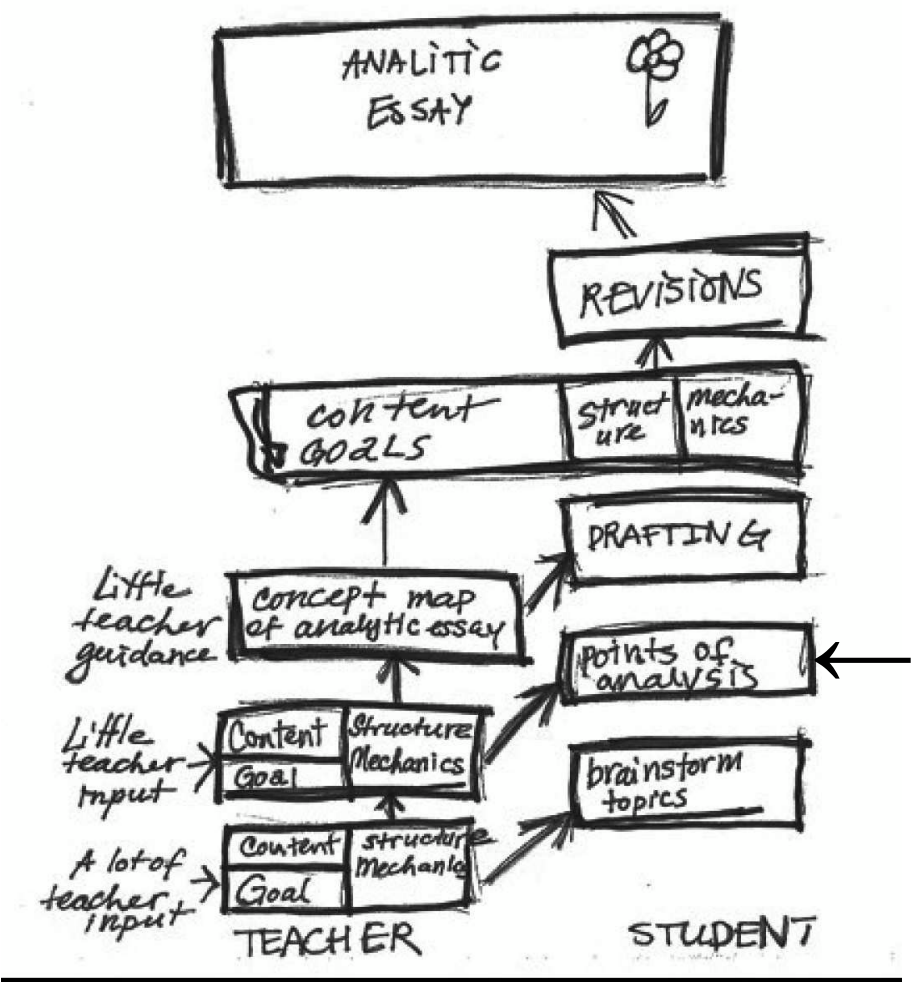

Figure 1: Post-teaching concept map of analytic essay unit curriculum, 11/7/2013

For this concept map, Sonja was asked to create a visual representation of her current understanding of the curriculum of the analytic essay unit - a repetition of the prompt she had completed prior to teaching the unit as well. In her pre-teaching concept map, Sonja had not included any reference to the concept of points of analysis, yet in the post teaching visual representation, this concept has become integrated into her instructional plans (marked with arrow in

figure 1) which involved asking students to "think of these uh like points of- possible points of analysis" before they begin drafting their essays (concept map 4, $11 / 7 / 2013)$. It is also here in the post-teaching concept map that Sonja first uses the term "points of analysis." While Sonja herself does not comment on the use of this new term in the explanation of the concept map, based on her comments regarding the analytic essay in the post-teaching interview it is possible to discern the meaning of this new term. In particular in the postteaching interview Sonja was again asked to "describe a successful analytic essay now (.) after you've taught this class" (interview 4, 11/7/2013). In her previous answer to this question prior to teaching the unit Sonja had little to say about how an analysis was actually accomplished, describing analysis as simply taking and issue "and you explicate it" while refraining from arguing (excerpt 1). After teaching the unit Sonja has much more to say about the actual process of analysis and her comments include an explicit focus on the related concepts which she now describes as the "parts of an issue" and the "perspectives" one can take on an issue.

\section{Excerpt 7:}

1 Sonja: uh a successful analytic essay has to properly narrow down or zoom into that topic um (.) the topic also has to be (.) um (.) analyzed from different points of view and that's sort of (.) like not every topic would $n$ - provide that luxury of (.) oh! you can look at this object from that perspective, and that perspective, and that perspective. and this is something that (.) I think as a genre an analytic essay pushes us to do, it makes us look at a topic or an issue as if it were an object and we look at this object, inspect that object from (.) different perspectives or using different methods kind of thing, (.) u:m (.) tch (.) a:nd (.) another thing tha:t (.) um (.) that is (.) very important for me from this ideational point of view it h:as to (.) [...] this analysis (.) is microscopic kind of like you 
look a:t (.) parts of that issue but you have to bring it back together and again zoom out and look at this object from um (.) uh (.) from a sort of more distant point of view and say how that feeds into the larger picture of a issue. (interview 4, 11/7/2013)

Compared to her pre-teaching description of the genre, this is a significantly more elaborated explanation of analysis. Rather than just "explicating" a topic, Sonja now describes analysis in terms of the related concepts of "parts of an issue" and "perspectives." As she explains, analysis involves first the mental practice of looking at "a topic or an issue as if it were an object" (7). Part of examining the topic as if it were an object involves taking a "microscopic" view and focusing in very close detail on the "parts of that issue" (10-11). These parts of the issue seem to be a new name for what Sonja has previously called "elements" or "units" of analysis. Another aspect of examining an issue as if it is an object involves inspecting "that object from (.) different perspectives " (8-9). Based on Sonja's inclusion of both of these related sub-concepts in her explanation, it is likely that the new term "points of analysis" in the concept map represents a superordinate term for both of these related analytic practices. Regardless of the exact nature of the relationship between these three terms of "points of analysis," "perspectives," and "parts of an issue," it is clear that these concepts do not represent merely peripheral concerns in Sonja's thinking about the analytic essay, but have in fact become central to Sonja's entire concept of analysis. Moreover, the systematic and hierarchical nature of this explanation with its various processes and sub-processes involved demonstrates that her initially spontaneous concept of analysis has become increasingly systematized into something much closer to the explicit and unpacked kind of scientific concept needed for teaching.

After the unit ended, Sonja reflected on what she believed she had learned through the process of teaching. Her comments demonstrate the importance she attached to what she learned about genre of the analytic essay.

\section{Excerpt 8:}

1 Sonja so(h) uh (.) even though we like to think of teachers as being experts and like I like

2 to think that oh! I am an expert you know in the class, but the truth is that

3

4

5

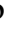

For Sonja, what she learned about "what an analytic essay is" and "how to teach that" are both part of the same process of concept development (lines 4-6). Through the process of teaching, and reflecting on her teaching in the stimulated recalls, Sonja not only gained new ways of explaining the central features of the genre to her students, she also gained a new and deeper understanding of the genre for herself. Importantly, Sonja's learning process did not start with a pre-determined understanding of the concept which she then systematically transformed into pedagogically appropriate forms. Instead, the development of her expert content knowledge and her PCK were largely indistinguishable. Both developed simultaneously in teaching activity and mediated reflection.

\section{Conclusion}

As the previous research on teachers' subject matter knowledge has shown, what teachers know about the content they teach involves complex mental processes. However, how teachers develop subject matter knowledge in and through their teaching practice has been less fully examined. This study has sought to contribute to our understanding of the ways in which teachers' knowledge of content can continue to develop as they engage in the activities of teaching. To accomplish this goal, a sociocultural theoretical perspective was adopted to examine how one teacher's concept of the genre of analysis and the related concept 
points of analysis developed through the process of teaching an analytic essay assignment in an L2 firstyear writing course.

Sonja's case demonstrates that teachers can and do continue to develop their understanding of the content that they teach through teaching. In Sonja's case, her understanding of the analytic essay at the beginning of the unit was an intuitive spontaneous concept (Vygotsky, 1986). It was through the process of teaching and reflecting on her teaching that Sonja was able to unpack and systematize this spontaneous concept into a more explicit scientific concept. Importantly, this process of developing her conceptualization did not take place prior to teaching, but it was in and through teaching that Sonja was able "to understand the meaning and functional significance of the sign forms one has been using all along" (Wertsch, 2007, p. 186).

This finding has important implications for both future research and teacher education practices. First, in terms of research, these results support the calls and arguments made by several critics of the PCK framework to take "teachers' subject knowledge seriously, by [. . . ] treating it as complex, dynamic and as situated as other categories of teachers' professional knowledge" (Ellis, 2007, p. 447). Part of taking subject matter seriously, is to acknowledge that teachers are not simply the conveyers, or even transformers, of pre-existing subject matter knowledge. Rather teachers actively adapt, reconstruct, and even "produce knowledge for teaching through their own experiences" (Park \& Oliver, 2008, p. 278). To say that teachers produce content knowledge through their teaching experiences is not to say that the content that is taught in language classrooms has nothing to do with the scholarly disciplines, but rather to recognize that what constitutes disciplinary knowledge and what constitutes language is constantly shifting and developing and to view classrooms as legitimate sites of knowledge creation.

Yet while learning new content for teaching is certainly possible, it is not automatic. Previous research has demonstrated the uneven and unpredictable nature of learning from teaching practice. Mere experience is no guarantee of teacher learning. Instead, teachers need a sufficient conceptual framework into which they can incorporate insights and sufficient support and opportunities for reflection in order to make use of the potential for content learning embedded in their teaching practices (Ball, 2000; Grossman, 1990). In Sonja's case, the research methods and particularly the guided reflection of the stimulated recalls functioned as an important source of mediation in Sonja's development by providing her with multiple opportunities to externalize her developing knowledge of the content she was teaching with the dialogic mediation of a knowledgeable other. This proved to be especially valuable as Sonja worked to unpack her intuitive, spontaneous concepts of the genre and how to teach it and abstracted scientific explanations from these intuitions. This result suggests that such structured opportunities for co-reflection that focus on integrating content, students, and pedagogy might have significant potential as a form of teacher supervision and professional development. 


\section{Appendix A: Stimulated Recall Question Bank}

- What do you remember thinking about as you were engaged in these moments of teaching?

- What were you trying to accomplish (i.e. what were your goals) in this moment?

- How do you understand the concept you or your students are interacting with?

- How did you understand your student's comment or question in the moment?

- How do you understand that comment or question now?

- What does this moment show you about the nature of the concept you are teaching?

- What does this moment show you about how your students understand the concept you are teaching?

\section{Appendix B: Transcription Conventions}

(.) very short pause

(2) timed pause

[word] overlapping talk

(word) indicates a guess at unclear or unintelligible talk

( ) talk occurs but is completely unintelligible

((laughter)) paralinguistic elements like laughter, gaze, or physical actions

wo(h)rd indicates the word is expressed with laughter wor- a word or stream of speech that has been cut off wo:rd indicates elongation of a sound

word a stressed word or syllable

$<$ word $>$ speech is slower that surrounding

$>$ word $<$ speech is faster than surrounding

, slightly rising intonation

? strongly rising intonation

. falling intonation

gesture indicates a gesture in the absence of speech

\section{Note}

1. Sonja refers to the concept in question by several terms throughout the unit. For clarity in the discussion I will use the final term Sonja used, points of analysis (in italics), to refer to the concept itself and will adopt Sonja's specific terminology in quotation marks (i.e. "units of analysis") to refer to her representations of the concept at specific moments in time.

\section{References}

Ball, D. L. (2000). Bridging practices: Intertwining content and pedagogy in teaching and learning to teach. Journal of Teacher Education, 51. 241-247. doi: $10.1177 / 0022487100051003013$

Ball, D. L., Thames, M. H., \& Phelps, G. (2008). Content knowledge for teaching: What makes it special? Journal of Teacher Education, 59, 389- 407. doi: 10.1177/0022487108324554

Cochran, K. F., DeRuiter, J. A., \& King, R. A. (1993). Pedagogical content knowing: An integrative model for teacher preparation. Journal of Teacher Education, 44(4), 263-272. doi:10.1177/0022487193044004004

Ellis, V. (2007). Taking subject knowledge seriously: From professional knowledg recipes to complex conceptualizations of teacher development. The Curriculum Journal, 18(4), 447-462.

Fenstermacher, G. D. (1994) The knower and the known: The nature of knowledge in research on teaching. In L. Darling-Hammond (Ed.), Review of research in education (pp. 3-56). Washington, DC: American Educational Research Association.

Grossman, P. L. (1990). The making of a teacher: Teacher knowledge \& teacher education. New York: Teachers College Press.

Grossman, P., Wilson, S. M., \& Shulman, L. S. (1989). Teachers of substance: Subject matter knowledge for teaching. In M. Reynolds (Ed.), Knowledge base for beginning teachers (pp. 23-36). Washington DC: American Association of Colleges for Teacher Education.

Gudmundsdottir, S. (1990). Values in pedagogical content knowledge. Journal of Teacher Education, 41(3), 44-52. doi:10.1177/002248719004100306

Gupta, S. (2012). Stuck on the couch. In Rosa, A. \& Escholz, P. (Eds.), Models for writers: Short essays for composition (11 $1^{\text {th }}$ ed). (pp. 535-538). Boston: Bedford/ St. Martens.

Hashweh, M. Z. (2005). Teacher pedagogical constructions: A reconfiguration of pedagogical content knowledge. Teachers and Teaching: Theory and Practice, 11(3), 273-292. 
Johnson, K. E. (2009). Second language teacher education: A sociocultural perspective. New York: Routledge.

Lantolf, J. P. \& Thorne, S. L. (2006). Sociocultural theory and the genesis of second language development. Oxford, UK: Oxford University Press.

Luhrmann, T. M. (2013, September 19). The violence in our heads. The New York Times. Retrieved from http:// www.nytimes.com/.

Park, S. \& Oliver, J. S. (2008). Revisiting the conceptualization of pedagogical content knowledge (PCK): PCK as a conceptual tool to understand teachers as professionals. Research in Science Education, 38, 261-284. doi:10.1007/s11165-007-9049-6

Shulman, L. S. (1987). Knowledge and teaching: Foundations of the new reform. Harvard Educational Review, 57(1), 1-22.

Shulman, L. S. \& Shulman, J. H. (2004). How and what teachers learn: A shifting perspective. Journal of Curriculum Studies, 36(2). 257-271.

Smagorinsky, P., Cook, L. S., \& Johnson, T. S. (2002). The twisting path of concept development in learning to teach. Teachers College Record, 105(8), 1399-1436.

Sockett, H. T. (1987). Has Shulman got the strategy right? Harvard Educational Review, 57(2), 208-219.

Verity, D. (Comp.). (2013). Teaching ESL 015 Composition for American Academic Communication II: A handbook for instructors. State College, PA: ESL/EAP Programs Department of Applied Linguistics, The Pennsylvania State University.

Vygotsky, L.S. (1986). Thought and language. Cambridge, MA: MIT Press.

Wertsch, J. V. (1985). Vygotsky and the social formation of mind. Cambridge, MA: Harvard University Press.

Wertsch, J. V. (1989). A sociocultural approach to mind: Some theoretical considerations. Cultural Dynamics, 2(2), 140-161. doi:10.1177/092137408900200202

Wertsch, J.V. (2007). Mediation. In H. Daniels, M. Cole, \& J.V. Wertsch (Eds.). The Cambridge companion to Vygotsky (pp. 178-192). New York: Cambridge University Press. 